\title{
ATTRACTING WOMEN TO AVIATION CAREERS: WHAT RECENT STUDIES REVEAL
}

\author{
Mary Ann Turney \\ Arizona State University East
}

\begin{abstract}
The percentage of women attracted to careers in aviation remains surprisingly low despite efforts by the industry to increase its talent pool by encouraging women to participate. This paper presents a review of literature relevant to the question of why the numbers of women choosing careers in aviation have not increased in the past two decades, and why even those who demonstrate an initial interest in the field eventually look for career satisfaction in other fields.
\end{abstract}

\section{INTRODUCTION}

Women continue to enter the workforce in increasingly larger numbers (Naisbitt \& Aburdene, 1990). Yet the talent pool of women available to the aviation industry is not increasing -- particularly in the technical side of the industry. Women still hold less than $6 \%$ of all FAA Airline Transport Pilot Certificates (U.S. Civil Airmen Statistics, 1998). The small number of women entering careers in aviation is evidenced in collegiate aviation where enrollment and retention of women remains low. Recent studies indicate that women are underrepresented in both aerospace engineering and aviation in general (Bowen \& Mathis, 1991).

Researchers have begun to ask why. Why do women remain under-represented in the aviation field despite governmental and industry policies which encourage women to join the aviation workforce? Studies that focus on women in science and engineering, and studies conducted specifically within the aviation environment, reflecting the experiences and perceptions of women, shed some light on why women are seriously underrepresented in aviation, and the factors that influence women in choosing and remaining in the field of aviation. The purpose of this paper is to report what recent studies reveal about attracting women to pursue careers in the field of aviation.

\section{DIFFERENCES IN LEARNING AND LEADERSHIP STYLES}

Differences in learning, leadership, and communication styles between men and women have been identified in several studies. Turney (1994) found that women learn in a cooperative, collaborative manner, often through conversation and sharing of ideas. Men prefer competition and debate, and frequently learn in a more autonomous style. Desjardens (1993) contrasted the leadership styles of women and men. She indicated that men wish to make important contributions, seek challenges, and exhibit a pattern of casual interaction with people in the workplace. Women, however, tend to be less concerned with their rank, are careful 
about risk-taking, and are attuned to the personal feelings and reactions of others.

\section{DIFFERENCES IN COMMUNICATION}

Research also indicates that communication styles of men and women differ considerably. Male language is direct and female language tends to be indirect and more subtle. Weiss (1993) reported that women used modifiers and query tags, often avoiding definitive statements. Sitler (1998) suggested that these characteristics might be related to confidence issues. She stated that women's language tends to contain metaphor, imagery and various superlatives, such as "Nothing is working," and men mistakenly take these expressions literally. Machado (1994) agreed with Tannen (1990) in stating that women were more inclined to "negotiate" in their communication styles. He said that men speak to exchange information and establish status, while women talk to exchange information and establish consensus.

Style "miscommunications" have a negative effect on women who consider aviation careers. Clear, concise, unambiguous, and rapid communication is a necessity in the cockpit. However, the assumption that women should automatically adapt the male style without training, or "wash out" of the program does not address the communication style issue.

\section{SOCIAL AND EMOTIONAL BARRIERS}

That aviation remains traditionally a male's career is evident in Eiff and Stitt's (1993) reports of social and emotional barriers facing women in aircraft maintenance environments. These include biased language, jokes, pictures, and non- acceptance by management. Women have not been prepared to confront these issues clearly and directly. In a male-oriented industrial setting, women are often not perceived as professional colleagues. Luedtke (1993) states that women in aviation careers "must cope with their own and others' resistance to their assumption of attitudes and behaviors necessary for effective leadership" (p. 38).

\section{ENROLLMENT IN TECHNICAL FIELDS}

Seymour and Hewitt (1997) report that enrollment and retention of students in technical fields has been a continuing area of concern among educators. They identified three dominant issues, namely (1) science and mathematics education was failing to foster science literacy in the population, (2) too few undergraduates and graduates were recruited and retained to meet the nation's future needs, and (3) the sciences recruited too exclusively among white males- thereby depriving the nation of the talents of women of all races and ethnicity, and of men of color (p. 1).

Seymour and Hewitt (1997) undertook a three-year study, aiming "to discover, and to establish the relative importance of, the factors with greatest bearing upon the decisions of undergraduates at four-year colleges and universities to switch from science, mathematics and engineering majors into disciplines which are not science based" (p.13). The issue of retention is of concern for both male and female students. They found that there are at least 26 factors which appear to influence retention and "what distinguished survivors from those who left was the development of particular attitudes or coping strategies" (p. 30). These coping strategies have yet to be defined. 


\section{WOMEN IN TECHNICAL FIELDS}

Persistence rates for men in technical fields varied between 61 percent at highly selective institutions and 39 percent for national samples. Comparative persistence rates for women, however, showed a high of only 46 and a low of 30 percent. While the absolute number of men leaving these programs is higher, the proportionate loss of women is greater and their underrepresentation actually increases as they progress in their undergraduate education (Seymour \& Hewitt, 1997, p. 5-7).

Seymour and Hewitt asked: "What would cause a large number of wellprepared, well-qualified young women, particularly those at highly selective institutions, to perform more poorly than their male counterparts in freshman and sophomore science and mathematics classes?" (p. 235). They identified the unique experiences of women in these programs, including coping with a misogynist tone set by faculty and negative attitudes and behavior of male peers ( $p$. 248).

\section{IMPACT OF THE "WEED OUT" SYSTEM ON WOMEN}

Traditional male education is based on the idea that young men should be challenged to test their mettle before being allowed to join adult males. This is the basis of the "weed-out" system. Women don't relate to this and see the system as very "male" and not applicable to them. They feel unwelcome and they perceive that men prefer to exclude women from these "trial" rituals (Seymour \& Hewitt, 1997, p. 259261).

\section{NEGATIVE EXPERIENCES WITH FACULTY}

Among173 women interviewed by Seymour and Hewitt, only eight reported a direct experience with faculty that was unacceptable. More common were "war stories" which were seen to convey the message that women were not welcome because their experiences were different. Some faculty also tended to make material seem more difficult than it is in order to build the mystique of a discipline (p. 260). Professors refer to students as "you guys" making some wonder if professors even see women since they socialize more with male students (Seymour \& Hewitt, 1997).

Women reported that they are sometimes assumed to be incompetent in "hands on" work, and complained of being ordered around, with faculty allowing their male peers to take charge, and give women help they did not ask for.

Another significant factor report-ed by Seymour and Hewitt was the need for setting the right tone from the top. Improving retention of students is not possible without the support from the institution's leadership.

\section{WOMEN'S CONFIDENCE}

Astin and Sax (1996) also explored the experiences of under-graduate women in the sciences. They addressed women's lack of self- confidence in their mathematical and scientific abilities, the lack of role models, parental and societal influence, and traditional teaching practices, as influencing their persistence rates in these programs. One interesting finding contradicted conventional wisdom. Astin and Sax (1994) found that interacting with faculty actually had a negative effect on women's mathematics confidence, the opposite effect of that observed in men. 
Graydon (1987) identified a lack of confidence in women in achievement situations that are perceived as sex-role inappropriate. Graydon stated: "Given that many sports are perceived as being masculine in nature, and are by definition competitive situations, it is not surprising that many women feel a lack of selfconfidence and therefore avoid the situation altogether by opting out. Some women of course do not opt out of competitive sports, they manage to overcome or avoid the selfconfidence trap, possibly due in some measure to positive socialization experiences, the complexity of which we are only just beginning to unravel" (p.57-58).

\section{RETENTION OF WOMEN IN COLLEGIATE AVIATION}

While the examination of women in science, mathematics, and engineering offers insights into the problem of the retention of women in aviation programs, research among aviation students indicates that this group faces unique problems.

Early gender-related research offers some basic insights. Lever's (1974) early studies suggest that women are initially not as prepared for aviation careers as men are. She determined that the games children play contribute to the preservation of typical sex role divisions in society by preparing boys with social skills required for careers and girls with skills required for raising families (p. 29-30).

Lather (1986) claimed that "woman's voice is one of empowerment" (p.65). Her study suggests that training approaches should be based on the empowerment of those being trained. She suggests that encouragement and empowerment should be built into the training design

Cockpit interactions and requirements present special challenges to those desirous of encouraging the participation of women in aviation. A recent study by Sitler (1998) identified a series of things instructor pilots should know about women so that they can support retention of women pilots and so that women don't drop out of flight training. These include:

1. Women are slower to gain confidence in the airplane.

2. Women require more flight hours before initial solo flights.

3. Women are more fearful of stalls, spins, and unusual attitudes.

4. Women are slower to grasp aerodynamics.

5. Women are quicker to grasp instrument flight.

6. Once women learn a procedure, they rarely vary it.

7. Women handle aircraft controls more smoothly.

8. Women have far fewer accidents in airplanes than men do (45-46).

According to Stuart (1999), "Women's need for more explanations [during flight training] may be an issue of confidence. She suggests that a woman is so afraid of doing something wrong that she wants to know all that she can about a flight maneuver before attempting it. Knowing all about it builds her confidence (p. 49). Regarding women's needs for a broader knowledge base, Tobin (1994) reported that women require a few more training hours to complete pilot training, but not significantly more according to studies she reviewed ( $\mathrm{p}$. 42). Tobin reported that females scored higher on academic qualification tests for 
U.S. Navy pilot selection, while men scored higher on mechanical and spatial apperception tests. She found that although the average flying score was identical, the number of aircraft hours flown by women students was slightly higher (not statistically significant) than those for the males. This finding correlates with Sitler's finding that women are slower to solo. Interestingly, Tobin's study found that the attrition rate for women in the Navy pilot training was less than $5 \%$ and almost $12 \%$ for men.

Stuart's in-depth study of 27 women pilots found that "aircraft were designed by men for men. If the airplane is adjustable to fit $90 \%$ of the men, it is not likely to fit $50 \%$ of the women. Of the 27 respondents [in her study], 18 reported problems with the fit of the aircraft they fly. Most problems for women are found with Cessna 152's and 172 's, the type aircraft used typically in flight training" (p. 49).

\section{CHALLENGES AHEAD}

Further studies are needed to focus specifically on the aviation environment and the experiences and perceptions of women students involved in aviation. Although gender balance is unlikely in the foreseeable future, the more women participate as aviation students, the more they teach faculty and peers how to behave toward women. But it is difficult in a predominantly male culture for women to change the atmosphere. If we are going to tap all the potential talent available to the aviation industry rather than just half the talent, it would appear useful to establish a comfortable climate for women. Further investigation is needed on how women learn, lead, and experience satisfaction in career development. 


\section{REFERENCES}

Astin, H. \& Sax, L. (1996). Developing scientific talent in undergraduate women. In C. Davis, A.B. Ginorio, C.S. Hollenshead, B.B. Lazurus, P.M. Rayman (Eds.), The equity equation (pp. 96-121). San Francisco: Jossey-Bass Publications

Bowen, B. \& Mathis, J.(1991, September). Women in aerospace engineering faculty of higher education. Frontiers in Education. American Society of Engineering Education. Purdue University.

Changing America: The new face of science and engineering final report. (1989, December). The Task Force on women, Minorities, and the Handicapped in Science and Technology.

Desjarens, C. (1993). Leadership competencies. National Institute for Leadership Development, Phoenix, AZ.

Eiff, G. \& Stitt, B. (1993). Some serious questions about women in aviation careers. St. Louis, MO: Fourth Annual Women in Aviation Conference.

Graydon, J.K. (1987). Psychological research and the sportswoman. In E. Adrian (Ed.), Sportswomen. New York: Karger.

Lather, P. (1986). Feminist perspectives on empowering research method. Proceedings of the 8th Annual Curriculum Theorizing Conference. 22-24 October. Reprinted Minnesota: Mankato State University.

Lever, J. (1994). Games children play: Sex differences and the development of role skills. Doctoral dissertation, Yale University, New Haven, CT.

Luedtke, J. (1993). Maximizing participation of women in collegiate aviation education. Doctoral dissertation. Wichita State University. (ERIC document reproduction service no. ED 359885)

Machado, R. (1994, January). A Happy Cockpit: Reducing Cockpit Stress Between the Sexes. Flight Training. 5. 50-52.

Naisbitt, J. \& Aburdene, P. (1990). Megatrends 2000. NY: William Morrow Co.

Potts, D. (1990, September 3). Bias lurks in all phases of qualitative research. Marketing News, 24, 12-13.

Seymour, E. \& Hewitt, N.M. (1997). Talking about leaving. Boulder, CO: Westview Press.

Sitler, R. L. (1998). The cockpit classroom: Women's perceptions of learning to fly and implications for flight curriculum and instruction. Doctoral Dissertation, Kent State University, Kent, Ohio. Magazine.

Stuart, R. (1999). Gender differences in the cockpit. New Zealand Wings

Tannen, D. (1990). You just don't understand: women and men in conversation. NY: Ballentine Books.

Tobin, L.L. (1994). Women military pilots: have perceptions and attitudes toward them changed in the last 15 years? Proceedings of the 5th Annual International Women in Aviation Conference 45-47. Lake Buena Vista, FL. 
Turney, M. A. (1994, October). Women's learning and leadership: Impact on CRM. Paper presented at the Fall Conference of the University Aviation Association. New Orleans, LA. (ERIC Document No. ED 377 7347).

United States Department of Transportation Federal Advisory Committee. (1993, August). Pilots and aviation maintenance technicians for the twenty-first century: Assessment of availability and quality. Washington DC: U.S. Government Printing Office.

Weiss, M. J. (1993, Fall) Integrating Communication and Gender In The Medical Setting. Proteus, A Journal of Ideas. 10. 55-59. 